\title{
The Teaching Assistant's Perspective on Flipping an Undergraduate Biome- chanics Course
}

\section{Dr. Christa M. Wille, University of Wisconsin, Madison}

Christa Wille is a Biomedical Engineering doctoral student at the University of Wisconsin-Madison. She received an undergraduate degree in Biomedical Engineering and went on to get her clinical doctorate in Physical Therapy at the University of Wisconsin-Madison. She advanced her clinical skills through a Sports Physical Therapy Residency at UW Health. Although continuing to practice Physical Therapy, Christa has returned to academia to continue to pursue research focused on gait analysis and the biomechanics of running related to various injuries including hamstring strains and injuries of the knee.

\section{Dr. Naomi C. Chesler, University of Wisconsin, Madison}

Naomi C. Chesler is Professor of Biomedical Engineering with an affiliate appointment in Educational Psychology. Her research interests include vascular biomechanics, hemodynamics and cardiac function as well as the factors that motivate students to pursue and persist in engineering careers, with a focus on women and under-represented minorities. 
The Teaching Assistant's Perspective on "Flipping" an Undergraduate Biomechanics Course

\author{
${ }^{1,2}$ Christa M. Wille, PT, DPT \\ ${ }^{1}$ Naomi Chesler, PhD \\ Departments of ${ }^{1}$ Biomedical Engineering and ${ }^{2}$ Orthopedics and Rehabilitation \\ University of Wisconsin-Madison, Madison, WI, USA
}

Corresponding Author:

Christa Wille, PT, DPT

Department of Biomedical Engineering

University of Wisconsin-Madison

2135 Engineering Centers Building

1550 Engineering Drive

Madison, WI 53706

cmwille@wisc.edu 


\begin{abstract}
Applications and outcomes of a flipped classroom in an engineering setting continue to be limited despite recognized advantages including positive gains in problem-solving skills, conceptual understanding, student retention, and student satisfaction. This paper focuses on the implementation of a flipped classroom for an undergraduate biomedical engineering introductory biomechanics course. To flip the classroom, content videos were created by teaching assistants (TAs) to provide a fist exposure to content material. Students were asked to watch videos prior to coming to class while in-class time was dedicated to practice and feedback via problem solving. With content disseminated in videos, valuable in-class time was spent utilizing team-based learning to solve problems in small groups of two to four based on self-selected seating arrangements.
\end{abstract}

A unique aspect of this course was the amount of input, participation, and leadership provided by a team of four graduate student TAs. With the guidance of an experienced faculty member, TAs recorded video lectures, prepared and led in-class and lab-based sessions, and created online homework assessments that could be automatically graded by the online course management system.

Successful implementation of a flipped classroom model was achieved and although challenges were encountered, the success of the course was based on course evaluations, student and teaching assistant feedback, and improvements in biomechanics related knowledge as assessed by concept inventory assessments. Knowledge acquisition over the course of the semester was demonstrated by a $38 \%$ gain score demonstrating increased knowledge using the Biomechanics Concept Inventory Version 3.

Although students reported mixed feedback for instructors and the course as a whole, primarily positive feedback was provided for the evaluation of the TAs participation in this course. Increased participation from TAs provided benefits including: improved participation and communication from students, appropriate integration of course content in regards to prerequisite knowledge and subsequent course follow-up, and efficient use of technology and online course management. In addition, TAs benefited immensely from added responsibilities including increasing their in-depth knowledge in the field of biomechanics and improving their teaching skills applicable to their future careers.

The purpose of this paper was to discuss the effectiveness of a flipped course model for both undergraduate students and graduate student instructors. The results may serve as a guide to encourage engineering educators to implement a flipped classroom for the benefit of all, including undergraduate students, graduate students, and the instructor of record. 


\section{Introduction}

The flipped classroom is a pedagogical model whereby the traditional lecture and practice or problem components of a course are reversed. The content-heavy lecture is usually provided in an online video format while valuable face-to-face classroom time is utilized for interactive group problems solving and discussion of difficult concepts. The flipped classroom model as it is now known was first introduced in the humanities discipline in 1998 by Walvoord and Anderson. Lage, Platt, and Treglia proposed a similar approach called the inverted classroom and applied it to an introductory economics course in 2000 [1]. Despite the growing popularity of the flipped classroom model in higher education, this model has received less attention in engineering [2]. The need for engineering graduates to be able to solve real-world problems and work in teams suggests the merit in flipping engineering courses. However, currently limited research exists on the impact of the flipped classroom model in engineering education [3].

Recognized advantages of a flipped classroom include positive gains in problem-solving skills, conceptual understanding, student retention, and student satisfaction [4]. Implementation of pedagogical methods such as a flipped classroom may prove beneficial when addressing common limitations in science, technology, engineering, and mathematics (STEM) disciplines such as long-term knowledge retention and student retention rates in STEM fields through to graduation. The long-term knowledge retention rates of material implemented in a flipped classroom are unknown, with some studies reporting improved long-term knowledge retention [5], while others report decreased knowledge retention [6]. Furthermore, student retention rates in STEM fields also remains a challenge. With $40 \%$ of students who enter a University in the United States with an interest in STEM and just $20 \%$ of STEM-interested underrepresented minority students finishing with a STEM degree [7], pedagogical improvements in STEM related fields are required to increase student participation and success to ensure the future of these fields.

Often in engineering courses teaching dynamics, such as biomechanics, it is challenging to connect the methods and theories being taught to practical applications a student may encounter in an engineering job setting. This may result in limited motivation for students to study dynamics related topics. Therefore, it is appropriate to implement innovated teaching approaches to address the limitations students find in mastering core biomechanics concepts. Pedagogical innovations demonstrating success include active learning as well as technology-based video-lectures and homework assignments. Active learning has been shown to result in decreased failure rates compared to traditional lecturing, $22 \%$ and $34 \%$ respectively, with higher exam scores following active learning [8]. Online homework is just as effective as paper-and-pencil homework $[9,10]$ and video lectures are as effective as in-person lectures at conveying basic information [11]. Thus, providing prerecorded video lectures for students provides a first exposure to the content, while limited face-to-face class time can be capitalized for interactive practice and feedback-based learning, and further exploration after class can be reserved for online homework [12]. Pre-recorded video lectures, interactive problem based learning, and online homework were key structures of the innovative teaching methods proposed in the flipped classroom model as described herein.

This paper focuses on the implementation of a flipped classroom for an undergraduate biomedical engineering introductory biomechanics course consisting of 77 junior and senior engineering students. Key aspects of this course included pre-recorded video lectures, interactive problem-based learning during in-class time, online homework, and applied examples of course content experienced during laboratory sessions. Unique assistance in the development of this course was provided by graduate students who provided significant contributions to the prep work needed to prepare a course for the flipped classroom model. The purpose of this paper was to determine the effectiveness and discuss qualitative outcomes of utilizing the knowledge and traits of experienced graduate students to assist with flipping an undergraduate biomechanics class. Successful 
outcomes of the proposed methods and recommendations for improvement are discussed to provide guidance to others interested in using the same model for flipping a classroom.

\section{Course Format}

Biomechanics (BME 315) is a core course required of all Biomedical Engineering (BME) students along with bioinstrumentation, biomaterials, and a six-semester design course sequence. This course introduces the mechanical behavior of biological tissues and systems. It is designed to enable students to analyze human movement by utilizing basic principles of engineering mechanics as tools for discovery and understanding. Principles of statics and dynamics, as applied to biomechanical systems, and concepts in mechanics of materials as applied to biological tissues, are reviewed and introduced. Students are provided an appreciation for the complex structures of biological tissues that contribute to material properties and biomechanical function. Aspects of human anatomy and physiology are introduced as appropriate for considering factors that enable human movement and for analyzing human movement. Methods for the analysis of both rigid-body and deformable-body mechanics are reviewed and introduced as they apply to biological tissues and systems. Students are expected to be engaged in online lectures, supplemental readings, homework, and classroom and laboratory exercises. Through these opportunities, students are expected to develop an understanding of important issues regarding the application of engineering tools in the study of biological structures and their function. Complete syllabus for the course is provided in the Appendix.

\section{Course Management System}

Canvas Infrastructure (Salt Lake City, UT) was used as an online learning platform to distribute all course content including pre-recorded content videos, lecture slides, in-class problems, additional review problems, laboratory manuals, and to administer and grade homework assignments. Additional features of the online course management system included discussion boards and a messaging system to provide a line of communication between instructors and students.

\section{Teaching Team}

One experienced faculty member served as the instructor of record and led a teaching team of four engineering graduate level teaching assistants (two doctoral-level, two masters-level). Due to unforeseen, unrelated circumstances, three biomechanics professors left the University within a three-month span prior to the start of the school year. Because the primary course content of whole-body, dynamics related-biomechanics was the not the focused field of research for the instructor of record, a strong team of teaching assistants (TAs) was recruited to assist with the implementation of this course. All teaching assistants were alumnus of the University's undergraduate BME program and specialized in biomechanics, with three having prior teaching experience. Required training for all engineering TAs included The New Educator Orientation (NEO) program designed to help instructors and TAs utilize effective teaching strategies and technologies in their classes. NEO workshops are intended to expose educators to new learning theories and approaches, as well as provide practical suggestions on how to improve teaching and learning. The program also provides TAs with information, resources, and training required as part of their employment. TAs were expected to work 15-18 hours per week and were provided a $35 \%$ appointment with a stipend and full tuition remission for compensation.

Given the extent of knowledge and experience amongst the TAs, the instructor of record encouraged TAs to become as active and involved as possible by giving the TAs the autonomy and authority to manage the online course management tool, create pre-recorded lectures, implement online homework, and complete course grading. A head-TA was assigned to take the primary lead for course management given her additional research and clinical biomechanics-related experience and her desire to pursue a career in academia. The faculty member met with the head-TA on a weekly basis to provide guidance, leadership, administrative assistance, and expertise on pedogeological methods for successful learning. 
Lecture Content

Pre-recorded lecture content is delivered in one-to-two ten-to-fifteen-minute videos made accessible to students through the online course management system, Canvas. Content covered in pre-recorded videos provides students with the first exposure to the material. Screencast videos were made through an audio and screen capture software (Camtasia 2018, TechSmith $^{\circledR}$, Okemos, MI) with voiceover annotating the provided lecture slides. Students were expected to watch the assigned lecture video and complete a short quiz online prior to coming to class. Online quizzes were graded to encourage student involvement and totaled to $5 \%$ of the students' final grade.

\section{In-Class Activities}

During scheduled in-class time, students were guided through applied examples and activities to provide opportunity for practice and feedback related to the content provided in the pre-recorded content videos. During in-class activities, students were encouraged to work in small groups for team-based learning. A variety of problem types were provided including multiple choice to test conceptual knowledge and computational problems to assess quantitative reasoning. To encourage as much active learning as possible, minimal lecturing was done in-class. Content review administered via lecture format in-class was limited to 5-10 minutes as needed when an additional review of difficult lecture content was requested by students. This was done at most once per week.

\section{Homework}

A thorough understanding of the concepts in the course and their applications were paramount to appreciating the intricacies of biomechanics. Thus, homework assignments were designed to reinforce students' understanding of topics covered and often served as the basis for exam questions. With the implementation of a flipped classroom, we chose to use the online course management tool to administer homework. Conceptual and computational questions comprised the homework assignments. Students were encouraged to work with classmates, but to ensure individual understanding of the homework the online management system was set up to automatically vary the values provided in computational problems while the problem statement remained the same. Partial credit was provided to the extent possible by breaking up a multi-step problem into subproblems and providing correct answers when necessary to move on and complete sequential steps successfully. To provide students with additional opportunities for practice and feedback, students were allowed two attempts on the homework with their final homework grade for each assignment taken as an average of the two attempts. This allowed students to identify which problems they got wrong after the first attempt and rework their solution. Correct answers were not provided until both attempts had been completed and the homework deadline had passed.

\section{Laboratory Sessions}

Through five laboratory sessions administered over the course of the semester, there is a substantial emphasis on developing technical analysis and reporting skills in this portion of the course. Laboratory topics include: balance and jumping (force plate analysis), skeletal muscle mechanics (muscle twitch and tetanus response), human motion analysis (kinematics), and mechanical testing of tendon and bone. The purpose of these exercises was to encourage students to develop practical skills in identifying processes for obtaining experimental information relevant to the solution of a biomechanical problem. Laboratory reports required a summary of the results, appropriately labeled plots and tables, and interpretation of results using a provided template. Students were encouraged to utilize current literature to guide their interpretations. They were provided with select references to consider and asked to cite any they utilized in their submitted lab reports. Team-based learning was encouraged through laboratory participation and report creation as students were allowed to work in teams of two-to-three for all labs. 


\section{Exams}

Four exams were administered throughout the semester, three mid-semester non-cumulative exams and one final cumulative exam. Exams were administered outside of scheduled class time and included multiple-choice and, short-answer questions, and free-response "long-answer" problems.

\section{Results}

Seventy-seven students were enrolled in the course. Success of the flipped modeled classroom was gauged based on mid-semester and end of semester qualitative and quantitative feedback from students and teaching assistants. Additional assessment of content-based knowledge gained was gauged using the Biomechanics Concept Inventory Version 3 ( $\mathrm{BCl} 3)$ [13]. Although the $\mathrm{BCl} 3$ was created and implemented primarily for kinesiology students, implementation of a concept inventory still holds merit for comparing improvement within individual students to gauge improvement.

\section{Mid-Semester Feedback}

Halfway through the semester, students provided written anonymous comments requesting additional feedback from course instructors. Primarily, students requested improvements to the homework grading process and a collective decision was made to allow increase the attempts to two for the homework assignments. Students were told after the first submission which answers were incorrect and allowed to revisit those problems and resubmit their answers. Final homework grades were reported as an average of the two attempts. Additional feedback was requested by the students in the form of more modeled working examples included in the prerecorded lecture videos or during in-class time. This concept was added to lecture videos and included during inclass time when possible. This allowed students to see a course instructor work through an example demonstrating one possible method and thought process to solve a computational problem.

At the mid-semester mark, TAs noted that they were becoming increasingly more comfortable with technology used for lecture capture and online course infrastructure. Additional tools were implemented using the online course platform such as modifying homework problems to include unique numbers and solutions within the same problem statement for each student. Although students were encouraged to work together for homework assignments, this ensured that students were able to come to an independent conclusion using the same methods. Additionally, although the head TA had taken responsibility with the initial set up of the course, at mid-semester the other TAs increased their participation in creating pre-recorded lectures and leading in-class sessions to share in the instructional responsibilities.

\section{Final Course Feedback}

Upon completion of the semester 39 out of 77 students completed post-course surveys evaluating the faculty instructor and the course as a whole (Figure 1). Despite mixed results from Likert outcome responses, positive feedback from open-ended questions was related to appreciation for the lecture videos, enjoying the flipped classroom more than expected, and general understanding of major course changes. Specific feedback from open-ended questions with positive feedback included the following examples:

"The only part of this class that was consistently really good was the lecture videos. They were short, but contained a sufficient amount of information. The only part of the class was an efficient use the students' time."

"I didn't mind the flipped classroom as much as I thought I would. I sometimes felt that we would get a lot of information in the video and then a lot of information in-class as well, not really getting to apply what we saw in the video."

"For this being the first semester of a flipped classroom in biomechanics I thought everything went well." 
As expected, there were several students who were hesitant toward the flipped classroom model. The most common feedback that was given on the course structure was related to the extra work students felt they were required to do, personal learning styles not matching the flipped classroom model, timeliness of posting prerecorded lectures. Examples of constructive criticism provided from other students as follows:

"Although they did a pretty good job, the structure of the class and organization was not optimal for learning the material; as a flipped classroom many of the topics in the lecture videos were not covered in in-person class sections."

"It would have been helpful if the videos for the whole week were uploaded over the weekend." "Flipped classrooms are, in theory, supposed to help students learn better. However, the problem is that they ultimately end up putting a lot more work on the student than would be in a normal lecture. As a modern-day student, forcing us to watch lecture on our own time AND go to the normally scheduled hour-long lecture AND then do problems from the homework just doesn't seem to be a feasible way for us to learn this material. Most students don't have the time to sit down and take an extra hour out of their day to watch a lecture video, when learning the material in-class and then doing problems on our own would help us learn, in my opinion faster."

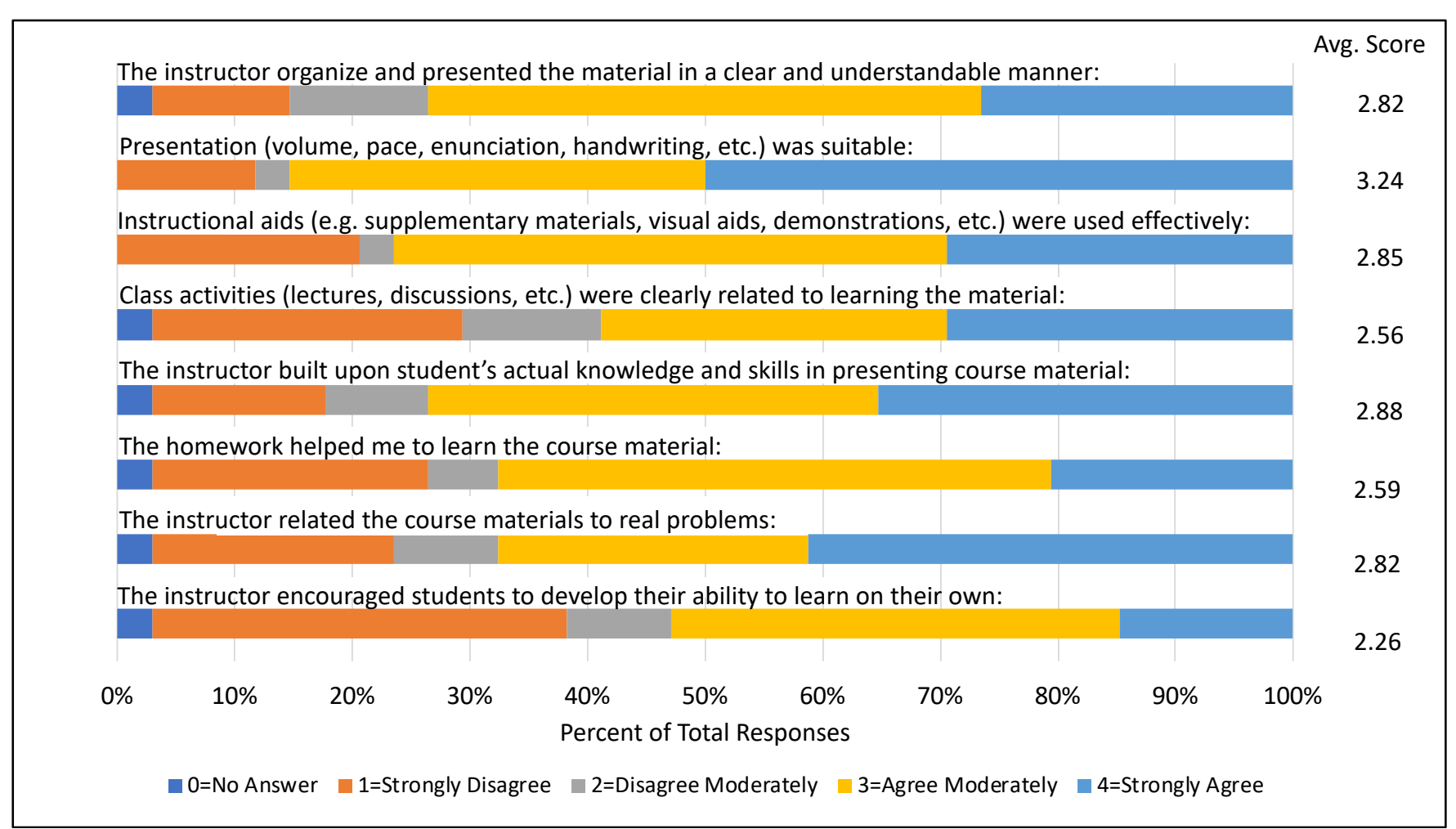

Figure 1. Student responses from completed post-course surveys evaluating the faculty instructor and the course as a whole. Potential responses and weighted values were: 0=No Answer, 1=Strongly Disagree, 2=Disagree Moderately, 3=Agree Moderately, 4=Strongly Agree. Thirty-nine students completed the evaluation, five students responded with No Answer to every question and those surveys have been removed from results. Average response score from all students is included at the right for each question.

\section{Feedback for the Teaching Assistants}

Upon completion of the semester 29 out of 77 students completed post-course surveys evaluating all teaching assistants, results for all four teaching assistants were pooled. Summative results of teaching assistant 
assessment surveys are presented in Figure 2. Teaching assistants were graded most highly on their willingness to help students but were given the lowest assessment on their ability to stimulate student interests.

Through specific feedback from open-ended questions, it was apparent that the TAs played a critical role in the success and implementation of the course. Examples of positive feedback for the TAs is as follows:

"The TAs are good at relating to the students."

"Kind, Engaging, flexibility on office hours, and always willing to answer questions."

"Willing to go above and beyond to help students."

"Showed interest in the students' learning both inside and out of the classroom."

Despite overwhelmingly positive feedback, specific examples of constructive criticisms for the TAs were as follows:

"TAs could improve teaching by continually updating material to ensure that all mistakes have been taken out and there are no contradictions between multiple TAs materials."

"One criticism might be that some of the homeworks did not have the right answers and double checking prior to sending it out might have saved time later on."

"Videos not uploaded early enough, errors in online homework."

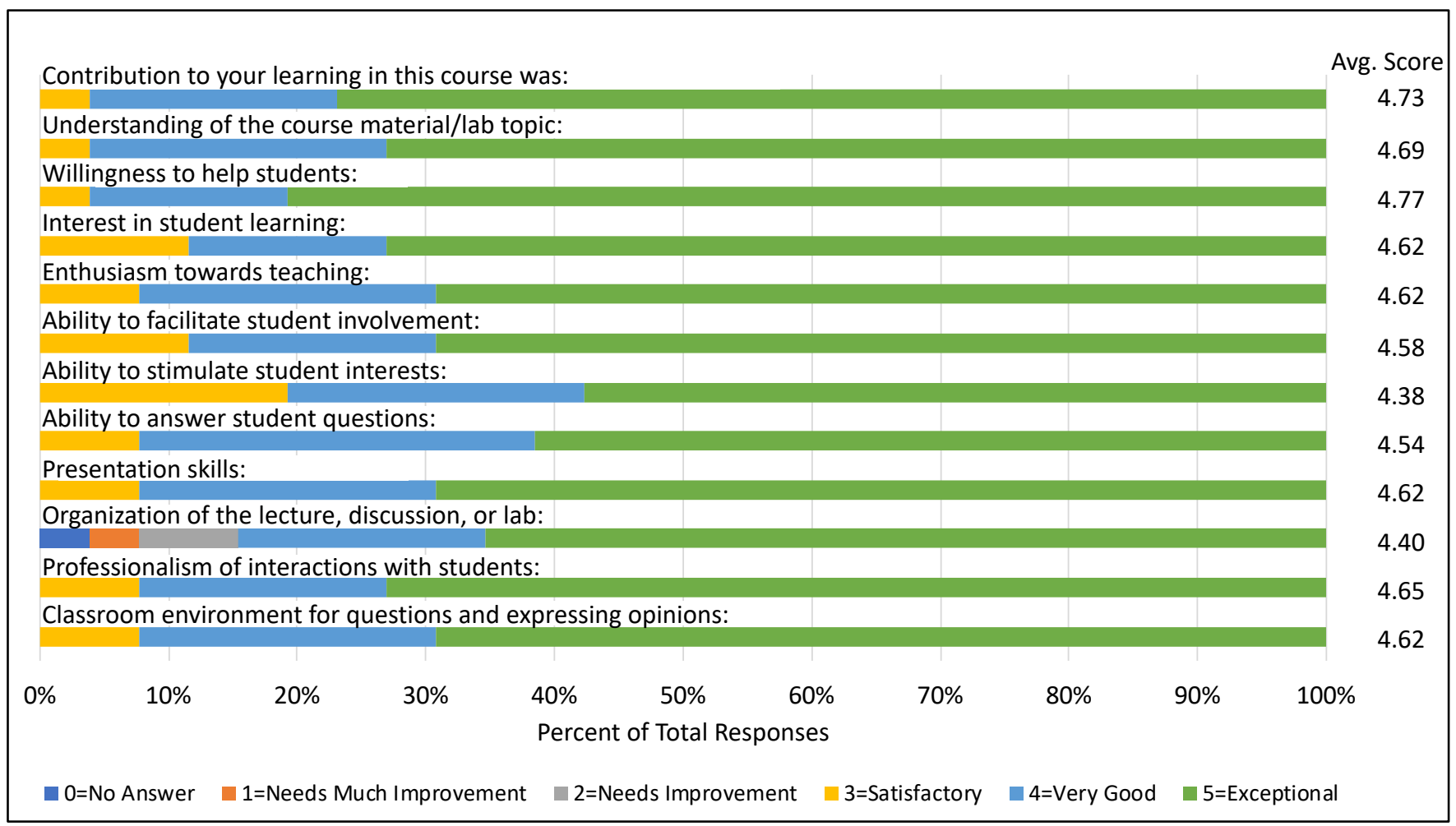

Figure 2. Student responses from completed post-course surveys evaluating all Teaching Assistants. Students were asked to evaluate their respective TA on the effects of the prompted skill or technique on the student's own participation or outcome in the course. Potential responses and weighted values were: $0=$ No Answer, $1=$ Needs Much Improvement, 2=Needs Improvement, 3=Satisfactory, 4=Very Good, or 5=Exceptional. Twenty-nine students completed the evaluation, three students responded with No Answer to every question and those surveys have been removed from results. Average response score from all students is included at the right for each question. 


\section{Feedback from the Teaching Assistants}

One TA provided unique feedback as he had assisted with the course twice, once with the traditional lecturebased class and a second time when it was flipped.

"Flipping the classroom made it a lot easier for me to get involved with the class and interact with the students. Flipping the class meant more of my time was spent working with students through problems and helping them understand rather than just grading homework assignments. I had the opportunity to watch the learning process happen rather than simply see the outcome on homework assignments. It was a lot more up-front work with the flipped environment but the results were more rewarding for me as an instructor."

Additional feedback from other TAs included:

"Overall, I think the flipped classroom can be very beneficial, especially for classes in math/engineering/physics that require problem solving and the application of learned concepts. However, I also think that it requires extra commitment from both the teaching staff, as well as the students. The teaching staff must ensure than the video lectures are relevant and timed appropriately to the problems covered in the lecture. The students themselves also have to honor this commitment and stay on top of the reading and the video lectures in order to get the most out of this experience."

\section{Biomechanics Concept Inventory}

In order to gauge student learning over the course of the semester, the Biomechanics Concept Inventory Version 3 (BCI3) $[13,14]$ was implemented prior to the start of the course and again upon the completion of the course. At the beginning of the semester students were able to on average answer 14 out of 24 questions appropriately based on their prior knowledge. Upon completion of the course, students answered an average of 18 questions correctly demonstrating an improvement of 3.8 points (Figure 3). Paired t-tests demonstrated a significant difference in biomechanics knowledge before and after the course $(p<0.001)$. Increase in knowledge over the course of the semester is also demonstrated by a $38.1 \%$ gain score, reported as a percent of the maximum possible improvement to be made based on the pre-test scores [15]. Normative data for $\mathrm{BCI} 3$ percent gain scores from a traditional lecture-based model for Kinesiology students at a different institution ranged from 24$29 \%[13,14]$.

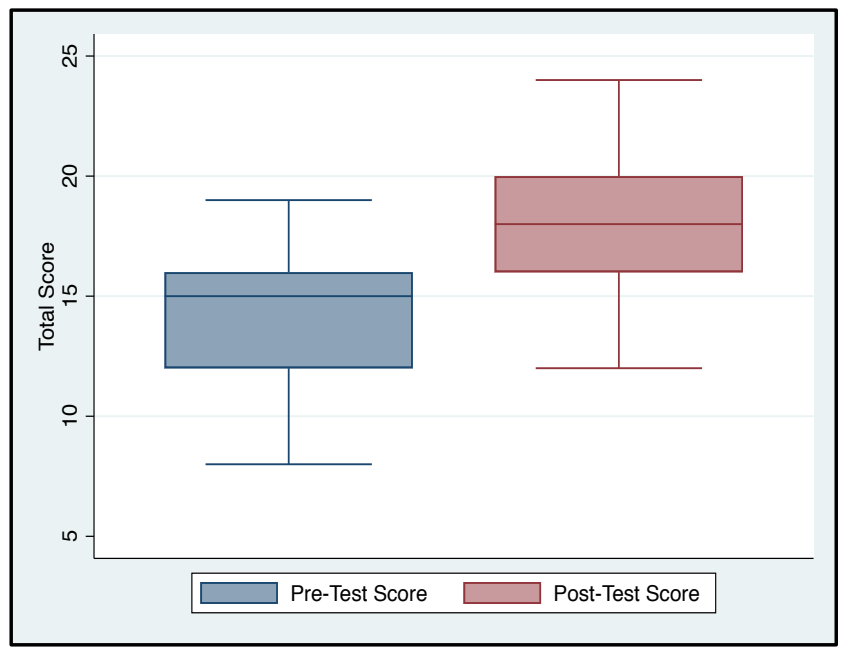

Figure 3. Box plots demonstrating the spread of data from the Biomechanics Concept Inventory of the preand post-test scores for junior and senior level biomechanics (BME 315). Results shown here demonstrate a $38 \%$ gain in knowledge over the course of the semester.

\section{Discussion}

Successful implementation of a flipped classroom model was achieved for a junior and senior level biomechanics course with the assistance of an experienced faculty member, talented TAs, and willing students. Although challenges were encountered, the success of the course was based on course evaluations, student and TA feedback, and improvements in biomechanics related knowledge as assessed by concept inventory assessments. 
A unique aspect of this course was the amount of input, participation, and leadership provided by a team of four graduate student TAs. With the guidance of an experienced professor, TAs recorded video lectures, prepared and led in-class and lab-based sessions, and created online homework assessments that could be automatically graded by the Canvas course management system. Increased participation from TAs provided benefits of student-centered learning including: improved participation and communication from students, appropriate integration of course content in regards to prerequisite knowledge and subsequent course follow-up, and efficient use of technology and online course management. The instructor model of this course allowed for the primary faculty member to help facilitate, rather than direct the course. This encouraged autonomy and accountability for the TAs and created opportunities for TAs to have input into the course structure and content allowing for shared investment in course outcomes. Student centered learning and instructor mentorship has been recommended as a method for the professional development of graduate student TAs [16]. As demonstrated through the implementation methods proposed in this course, more mindful and purposeful interaction between TAs and course instructors can help to enrich and enhance the learning environment for both the students who take the course and the graduate students who help facilitate the course.

Engaging TAs above and beyond traditional teaching models to involve them in course content development provided additional benefit to students taking the course, including the ability to relate to their TAs and better motivate student participation. In addition, TAs benefited immensely from added responsibilities including increasing their in-depth knowledge in the field of biomechanics and improving their teaching skills applicable to their future careers. Regardless of the specific setting, the ability to disseminate knowledge and provide leadership are skills that are essential to the success of any graduate student.

Success of the course was also gauged in part from student outcomes and feedback. Qualitative feedback from students presented mixed responses. As expected, students did have initial apprehension and resistance to the flipped course model. However, comments such as, "I didn't mind the flipped classroom as much as I thought I would" indicate students were open-minded to the course model and found value in the online-videos, "... the lecture videos [were] consistently really good." Conversely, given the extent of the preparatory work required to implement a flipped classroom constructive criticism provided by the students included recommendations to post lecture videos early to allow students to work ahead and feedback to correct mistakes that were overlooked by students in their online homework. Thankfully students were patient and willing to provide this feedback to ensure sequential offerings of this course would operate more smoothly.

Likert survey outcome measures for the instructor of record and the course as a whole demonstrated positive feedback on seven out of eight questions (51-74\% of the respondents answering Moderately or Strongly Agree). Unfortunately, the opportunities provided to the TAs to take the primary lead of the course resulted in mixed reflections of the faculty member who served as the instructor of record for this course. Although her level of involvement in the course was intentional given the proven ability of the TAs to handle course instruction, her limited participation in the course was perceived with mixed student emotions. In addition, gender bias against the female instructor of record could be influencing students to interpret limited involvement as lack of knowledge [17]. Therefore, Likert scoring feedback for the primary instructor of record is difficult to interpret. Future implementation of a course with primary TA lead should be clearly explained with detailed expectations to the undergraduate students participating in the course.

Quantitative assessment of the success of the course was evaluated with the $\mathrm{BCl}$. Students in this course showed an improvement via normalized gain scores of $38 \%$ while normative values reported following traditional lecture-based methods at a different institution show improvements of $24-29 \%$. Although direct conclusions cannot be made across different departments and institutions, it remains possible that the flipped classroom model aided in the improved normative gains reported for the biomechanics class included in this study. Despite significant gains in biomechanics related knowledge shown upon the completion of the semester, students demonstrated the ability to correctly answer only $75 \%$ of the concepts tested in the post-course 
evaluation. This highlights the continued challenges in teaching mechanical and dynamics-based content and the need for continued attention to identify the most successful means of pedagogy used when teaching similar courses.

Future work to continue to advance the success of the flipped biomechanics classroom model discussed here includes continuing to monitor the quantitative and qualitative feedback of sequential course offerings. As with any change course structure, it is likely that improvements in course structure will be seen with the second or third iteration of a course. Continued research should assess the long-term retention of student knowledge with the implementation of the $\mathrm{BCl} 3$ 12-months beyond the completion of the course. In addition, more defined learning objectives could be outlined to help guide student expectations and assessment of success. For example, basic learning objectives could be administered for each pre-recorded lecture video, while advanced learning objectives can be outlined for students to meet following in-class active learning time. Furthermore, advancements in online course management tools allow specific quiz, homework, and exam questions to be tied to well-defined learning objectives providing immediate feedback to course instructors to implement change in course structure as needed. Although current literature demonstrates initial success of the flipped classroom model for STEM disciplines, continued efforts are needed to ensure these methods are the most effective longterm.

\section{Conclusion}

Successful implementation of a flipped classroom model was achieved for a junior and senior level biomechanics course with the assistance of an experienced faculty member, talented TAs, and willing students. Pre-recorded video lectures created by TAs for first exposure, interactive problem-based learning implemented during faceto-face class time, and online homework regulated by TAs were key structures of the innovative teaching methods proposed in the flipped classroom model as described herein. Engaging TAs who are technologically savvy and have a strong ability to connect with undergraduate students may serve as a unique aspect to addressing both knowledge and student retention in STEM based fields through interactive learning. The results may serve as a guide to encourage engineering educators to implement a flipped classroom for the benefit of all, including undergraduate students, graduate students, and the instructor of record. 


\section{References}

[1] Lage MJ, Platt GJ, and Treglia M. "Inverting the classroom: A gateway to creating an inclusive learning environment." The Journal of Economic Education 31: 30-43. 2000.

[2] Mason GS, Shuman TR, and Cook KE, "Comparing the Effectiveness of an Inverted Classroom to a Traditional Classroom in an Upper-Division Engineering Course." IEEE Trans on Education, 2013, pp 1-6.

[3] Kerr B. "The flipped classroom in engineering education: A survey of the research." Interactive Collaborative Learning (ICL), International Conference. 2015 Sep 20 (pp. 815-818). IEEE.

[4] Bishop JL, Verleger MA. "The flipped classroom: A survey of the research." Proceedings from ASEE national conference. Atlanta, GA 2013 Jun 23 (Vol. 30, No. 9, pp. 1-18).

[5] Shatto B, L'ecuyer K, Quinn J. "Retention of content utilizing a flipped classroom approach." Nursing education perspectives. $2017 \mathrm{Jul}$ 1;38(4):206-8.

[6] Taglieri C, Schnee D, Camiel LD, Zaiken K, Mistry A, Nigro S, Tataronis G, Patel D, Jacobson S, Goldman J. "Comparison of long-term knowledge retention in lecture-based versus flipped team-based learning course delivery." Currents in Pharmacy Teaching and Learning. 2017 May 1;9(3):391-7.

[7] PCAST STEM Undergraduate Working Group. "Engage to Excel: Producing One Million Additional College Graduates with Degrees in Science, Technology, Engineering, and Mathematics." Eds Gates SJ, Jr, Handelsman J, Lepage GP, Mirkin C. 2012.

[8] Freeman S, Eddy SL, McDonough M, Smith MK, Okoroafor N, Jordt H, Wenderoth MP. "Active learning increases student performance in science, engineering, and mathematics." Proceedings of the National Academy of Sciences. 2014 Jun 10;111(23):8410-5.

[9] Bonham SW, Deardorff DL, and Beichner RJ. "Comparison of student performance using web and paperbased homework in college-level physics." Journal of Research in Science Teaching, 40(10):10501071, 2003.

[10]Fynewever H." A comparison of the effectiveness of web-based and paper-based homework for general chemistry." The Chemical Educator, 13(4):264-269, 2008.

[11]Zhang D, Zhou L, Briggs RO, and Nunamaker JF. "Instructional video in e-learning: Assessing the impact of interactive video on learning effectiveness." Information \& Management, 43(1):15-27, 2006.

[12]Walvoord BE, and Anderson VJ. "Effective grading: A tool for learning and assessment." San Francisco: Jossey-Bass. 1998.

https://cla.auburn.edu/cla/assets/docs/assessment/Summary\%20of\%20Walvoord\%20and\%20Anderson \%20Effective\%20Grading.pdf. Date Accessed 22 March, 2019.

[13] Knudson D. "Biomechanics concept inventory." Perceptual and motor skills. 2006 Aug;103(1):81-2.

[14] Knudson D. "Biomechanics concept inventory: Version two". ISBS-Conference Proceedings Archive 2004. Ottawa, Canada.

[15] Hake, A.A. "Interactive-engagement versus traditional methods: a six-thousand-student survey of mechanics test data for introductory physics." American Journal of Physics, 66, 64-74. 2998.

[16]Rosales J, Spracklin-Reid D, Caines S. "Effective use of graduate students as teaching assistants in undergraduate engineering education." Proceedings of the Canadian Engineering Education Association. 2013 Jun 17.

[17] MacNell L, Driscoll A, Hunt AN. "What's in a name: Exposing gender bias in student ratings of teaching." Innovative Higher Education. 2015 Aug 1;40(4):291-303. 
Appendix. Biomechanics (BME 315) course syllabus.

BME 315 - Biomechanics, Fall 2018

\begin{tabular}{|c|c|c|c|}
\hline $\begin{array}{l}\text { Week, } \\
\text { Date }\end{array}$ & Topic (Book Sections) & Sub-Topics & HW \& Lab \\
\hline $\begin{array}{l}1 \\
9 / 6(T h)\end{array}$ & Introduction & - $\quad$ Review of Syllabus & $\begin{array}{ll} & \text { Biomechanics Pre- } \\
& \text { Course Concept Quiz }\end{array}$ \\
\hline $\begin{array}{l}2 \\
9 / 11\end{array}$ & $\begin{array}{l}\text { Movement Terminology } \\
\text { (Ozkaya 2; Herman 2) }\end{array}$ & $\begin{array}{ll}\text { - } & \text { Anatomical planes } \\
\text { - } & \text { Anatomical movements } \\
\text { - } & \text { Types of joints } \\
\end{array}$ & $\begin{array}{ll}- & \text { HW } 1 \\
\text { - } & \text { Lab } 1-\text { Balance and } \\
& \text { Jumping: Force Plate } \\
& \text { Analysis } \\
\end{array}$ \\
\hline $9 / 13$ & Force Vectors & $\begin{array}{ll}\text { - } & \text { Forces (types, systems) } \\
\text { - } & \text { Postural control } \\
\text { - } & \text { Force plates } \\
\text { - } & \text { Center of pressure } \\
\text { - } & \text { 3D motion } \\
\end{array}$ & \\
\hline $\begin{array}{l}3 \\
9 / 18\end{array}$ & $\begin{array}{l}\text { Moment Vectors } \\
\text { (Ozkaya 3, 5; Lieber 3; } \\
\text { Herman 2) }\end{array}$ & $\begin{array}{ll}\text { - } & \text { Moment vectors } \\
\text { - } & \text { Anthropometry }\end{array}$ & - $\quad \mathrm{HW} 2$ \\
\hline $9 / 20$ & $\begin{array}{l}\text { Systems in Equilibrium } \\
\text { Muscles } \\
\text { (Ozkaya 4, 5; Herman 2; } \\
\text { Lieber 3) }\end{array}$ & $\begin{array}{ll}\text { - } & \text { Free body diagrams } \\
\text { - } & \text { Conditions for equilibrium } \\
\text { - } & \text { Muscle moment arms } \\
\text { - } & \text { Trusses and frames in } \\
& \text { biomechanics } \\
\text { - } & \text { Muscle redundancy } \\
\end{array}$ & \\
\hline $\begin{array}{l}4 \\
9 / 25\end{array}$ & $\begin{array}{l}\text { Muscles } \\
\text { (Ozkaya 5; Lieber 3) }\end{array}$ & $\begin{array}{ll}\text { - } & \text { Muscle structure } \\
\text { - } & \text { Cross-bridge mechanics } \\
\text { - } & \text { Force-length property of } \\
\text { - } & \text { muscle } \\
\text { - } & \text { Opypes of contractions } \\
\text { Optimal design of muscle }\end{array}$ & $\begin{array}{ll}- & \text { HW } 3 \\
- & \text { Lab } 2-\text { Muscle } \\
\text { Contraction } \\
\text { Properties: E-Stim } \\
\text { Experiments }\end{array}$ \\
\hline $9 / 27$ & Muscles Continued & $\begin{array}{ll}\text { - } & \text { Muscle architecture } \\
\text { - } & \text { Force-velocity property of } \\
\text { muscle }\end{array}$ & - $\quad \mathrm{HW} 4$ \\
\hline $\begin{array}{l}5 \\
10 / 2\end{array}$ & $\begin{array}{l}\text { Neuromotor System } \\
\text { (Ozkaya 5, 15; Lieber 1, 2; } \\
\text { Herman 5; Ethier 8) }\end{array}$ & $\begin{array}{ll}\text { - } & \text { Neuromuscular junction } \\
\text { - } & \text { Excitation-contraction } \\
\text { - } & \text { Twitch and tetanus } \\
\text { - } & \text { Fiber types } \\
\text { - } & \text { Motor units } \\
\end{array}$ & \\
\hline $10 / 4$ & $\begin{array}{l}\text { Exam Review } \\
\text { EXAM 1 } \\
\text { 5:30-7p }\end{array}$ & & \\
\hline $\begin{array}{l}6 \\
10 / 9\end{array}$ & $\begin{array}{l}\text { Particle Dynamics } \\
\text { (Ozkaya 6-10) }\end{array}$ & $\begin{array}{ll}\text { - } & \text { Terminology } \\
\text { - } & \text { Linear/Curvilinear kinematics }\end{array}$ & - $\mathrm{HW} 5$ \\
\hline $10 / 11$ & Particle Dynamics & $\begin{array}{ll}\text { - } & \text { Angular kinematics } \\
\text { - } & \text { Kinetics (Newton's } 2^{\text {nd }} \text { Law) } \\
\end{array}$ & \\
\hline $\begin{array}{l}7 \\
10 / 16\end{array}$ & Particle Dynamics & $\begin{array}{ll}\text { - } & \text { Kinetics (Newton's } 2^{\text {nd }} \text { Law) } \\
\text { - } & \text { Alternate formulation of } \\
\text { - } & \text { Euwton's } 2^{\text {nd }} \text { Law } \\
\text { - } & \text { Mass moment of inertia } \\
\text { - } & \text { Radius of gyration }\end{array}$ & - $\quad \mathrm{HW} 6$ \\
\hline
\end{tabular}




\begin{tabular}{|c|c|c|c|}
\hline $10 / 18$ & $\begin{array}{l}\text { Work and Energy } \\
\text { (Ozkaya 8) }\end{array}$ & $\begin{array}{ll}- & \text { Mechanical work } \\
\text { - } & \text { Potential and kinetic energy } \\
\text { - } & \text { Work-energy principle } \\
\text { - } & \text { Metabolic energy } \\
\end{array}$ & \\
\hline $\begin{array}{l}8 \\
10 / 23\end{array}$ & $\begin{array}{l}\text { Walking } \\
\text { (Ethier 10; Herman 3) }\end{array}$ & $\begin{array}{ll}\text { - } & \text { Gait cycle } \\
\text { - } & \text { Basic gait metrics } \\
& \text { Inverted pendulum model of } \\
\text { - } & \text { walking } \\
\text { - } & \text { Pnergy fluctuations in walking } \\
\text { - } & \text { Ground reaction forces during } \\
& \text { walking } \\
\end{array}$ & $\begin{array}{ll}- & \text { HW } 7 \\
- & \text { Lab } 3-\text { Human Motion } \\
& \text { Analysis: Kinematics }\end{array}$ \\
\hline $10 / 25$ & Running & $\begin{array}{ll}- & \text { Center of pressure } \\
\text { - } & \text { Walk-to-Run transition } \\
\text { - } & \text { Energy fluctuation in running } \\
\text { - } & \text { Spring-mass model of running } \\
\text { - } & \text { Energy storage in running } \\
\text { - } & \text { Basic model } \\
\end{array}$ & \\
\hline $\begin{array}{l}9 \\
10 / 30\end{array}$ & Motion Capture & $\begin{array}{ll}\text { - } & \text { Motion capture systems } \\
\text { - } & \text { Applications } \\
\text { - } & \text { Inverse kinematics } \\
\text { - } & \text { Inverse dynamics } \\
\end{array}$ & \\
\hline $11 / 1$ & $\begin{array}{l}\text { Exam Review } \\
\text { EXAM II } \\
\mathbf{5 : 3 0 - 7 p} \\
\end{array}$ & & \\
\hline $\begin{array}{l}10 \\
11 / 6\end{array}$ & $\begin{array}{l}\text { Impulse and Momentum } \\
\text { (Ozkaya 11) }\end{array}$ & $\begin{array}{ll}\text { - } & \text { Impulse Momentum Theorem } \\
\text { - } & \text { Collision } \\
\text { - } & \text { Conservation of Energy } \\
\end{array}$ & $\begin{array}{ll} & \text { HW } 8 \\
- & \text { Lab 4-Tendon } \\
& \text { Mechanics: Tensile } \\
& \text { Loading }\end{array}$ \\
\hline $11 / 8$ & $\begin{array}{l}\text { Tendon/Ligament } \\
\text { (Ozkaya 15; Ethier 9; } \\
\text { Ozkaya 13,14; Humphrey 2) }\end{array}$ & $\begin{array}{ll}\text { - } & \text { Material composition } \\
\text { - } & \text { Terminology } \\
\text { - } & \text { Stress-strain curve following } \\
& \text { axial loading } \\
\text { - } & \text { Material properties } \\
\text { - } & \text { Poisson's Ratio } \\
\text { - } & \text { Multi-axial loading }\end{array}$ & \\
\hline $\begin{array}{l}11 \\
11 / 13\end{array}$ & Tendon/Ligament & $\begin{array}{ll} & \text { Mechanical properties } \\
\text { - } & \text { Viscoelastic properties } \\
\text { - } & \text { Viscoelastic models } \\
\end{array}$ & - $\quad$ HW 9 \\
\hline $11 / 15$ & Tendon/Ligament & $\begin{array}{ll}\text { - } & \text { Viscoelastic properties } \\
\text { - } & \text { Viscoelastic models } \\
\text { - } & \text { Musculoskeletal function }\end{array}$ & \\
\hline $\begin{array}{l}12 \\
11 / 20\end{array}$ & Bone (Ethier 9, Ozkaya 15) & $\begin{array}{ll}- & \text { Bone composition } \\
\text { - } & \text { Bone micro-structure, } \\
& \text { mechanics } \\
\end{array}$ & - $\mathrm{HW} 10$ \\
\hline $11 / 22$ & THANKSGIVING & - No Class & \\
\hline $\begin{array}{l}13 \\
11 / 27\end{array}$ & Bone & $\begin{array}{ll}\text { - } & \text { Cortical and trabecular bone } \\
\text { mechanics } \\
\text { - } \\
\text { Density-dependent material } \\
\text { properties } \\
\text { - Osteoporosis } \\
\end{array}$ & $\begin{array}{l}\text { HW } 11 \\
\text { Lab 5-Bone } \\
\text { Mechanics: 3-Point } \\
\text { Bending }\end{array}$ \\
\hline $11 / 29$ & $\begin{array}{l}\text { Bone Loading } \\
\text { Bone Failure Analysis }\end{array}$ & $\begin{array}{l}\text { - Stress quantities due to } \\
\text { common loads } \\
\text { - } \quad \text { Combined loading }\end{array}$ & \\
\hline
\end{tabular}




\begin{tabular}{|c|c|c|}
\hline & & $\begin{array}{ll}\text { - } & \text { Stress element } \\
\text { - } & \text { Failure criteria } \\
\text { - } & \text { Direct stress v. Principal } \\
& \text { stresses } \\
\text { - } & \text { Mohr's Circle }\end{array}$ \\
\hline $\begin{array}{l}14 \\
12 / 4\end{array}$ & $\begin{array}{l}\text { Exam III Review } \\
\text { EXAM III } \\
\mathbf{5 : 3 0 - 7 p}\end{array}$ & \\
\hline $12 / 6$ & Guest Lecture & $\begin{array}{l}\text { Cartilage Mechanics and } \\
\text { Mechanobiology }\end{array}$ \\
\hline $\begin{array}{l}15 \\
12 / 11\end{array}$ & Guest Lecture & Cardiovascular Mechanics \\
\hline
\end{tabular}

FINAL EXAM: Wednesday, December 19, 10:05-12:05p 